\title{
VARIACIÓN EN FORMA MORFOLÓGICA DE LOS PRONOMBRES DE PRIMERA Y SEGUNDA PERSONA DE PLURAL ${ }^{1 *}$
}

\author{
ANTONio FÁbregas \\ CAS-Universitet $i$ Troms $\emptyset$
}

\begin{abstract}
RESUMEN
En este trabajo se analiza una propiedad de los pronombres personales del español que no ha sido frecuentemente estudiada: el hecho de que las formas de primera y segunda persona plural son morfológicamente complejas (nos-otros, vos-otros). Se propone relacionar este hecho con otro fenómeno tipológicamente excepcional de esta lengua, las discordancias de persona con sujetos plurales (los estudiantes queremos aprobar; los estudiantes queréis aprobar). En un marco estrictamente sintáctico para el análisis de los procesos morfológicos se propondrá que ambos fenómenos son consecuencia de una estrategia para evitar una configuración semántica no interpretable.
\end{abstract}

Palabras clave: sujetos, pronombres, concordancia, plural, relación entre morfología y sintaxis.

\section{Abstract}

In this article we analyse a property of personal pronouns in Spanish which, to the extent of our knowledge, has not been studied in depth in the previous literature: the fact that the first and second person plural pronouns are morphologically complex (nos-otros, 'us-others', vos-otros, 'you-others'). We propose to relate this phenomenon with another typological exception which Spanish exhibits: the discordances in person with some plural subjects (los estudiantes queremos aprobar, 'The students want. $1 \mathrm{pl}$ pass the exam'; los estudiantes queréis aprobar, 'The students want.2pl pass the exam'). In a strictly syntactic framework for the study of morphological processes we will propose that both phenomena are related to each other as consequences of the same strategy to avoid a semantically uninterpretable configuration.

Key Words: subjects, pronouns, agreement, plural, relationship between morphology and syntax.

${ }^{1 *}$ La investigación que subyace a este proyecto ha sido posible gracias a la beca post-doctoral EX2006-0968 del MEC. Este trabajo se ha beneficiado considerablemente de los comentarios de Manuel Leonetti, Tarald Taraldsen, Peter Svenonius, Ignacio Bosque y Daniel Harbour. Agradezco, asimismo, su ayuda a mis informantes Minjeong Son, Pavel Caha, Lucie Medova, Youssuf Islam, Isabelle Roy, Bianca Basciano y Christian Uffmann. Todo error que permanezca en este trabajo es de mi exclusiva responsabilidad. En este trabajo usamos las siguientes abreviaturas: ing. (inglés), fr. (francés), it. (italiano), ár. eg (árabe egipcio), che. (checo), co. (coreano), cat. (catalán), por. (portugués), gal. (gallego), pl. (plural), тор (тóPICO), 1 (primera persona), NUM (número), N (sustantivo). 


\section{Planteamiento general del artículo}

Hay dos propiedades de los pronombres personales que han sido ampliamente estudiadas en la bibliografía: los distintos rasgos morfosintácticos que estas palabras contienen -distinciones de persona, número, definición y caso (Corbett 1991, Haspelmath 1997, Harley y Ritter 2002a, 2002b, Harbour 2006, Bhat 2004) - y su descomposición interna (Postal 1969, Abney 1987, Ritter 1995, Cardinaletti 1994, Cardinaletti y Starke 1999, Fukui 1987, Radford 1993, Corver y Delfitto 1997, Koopman 2000, Panagiotidis 2002, Déchaine y Wiltschko 2002). Por lo general, los estudios que se ocupan de la primera cuestión son elaborados por tipólogos y morfólogos, mientras que la segunda cuestión ha sido más bien tratada por sintactistas y semantistas. Esto ha hecho que exista un hueco en el estudio de los pronombres personales, concretamente el problema ilustrado por el contraste de (1).

(1) a. Ing. we, fr. nous, it. noi, ár. eg. nahnu

b. Esp. nosotros, cat. nosaltres, gal. nosoutros

El factor crucial en los datos de (1) es el contraste que se produce entre la materialización morfológica de la primera persona del plural y el hecho de que los rasgos sintácticos y semánticos que expresan son los mismos. En las lenguas de (1a) se emplea una forma morfológicamente simple para dar cuenta exactamente de los mismos rasgos que en las lenguas del segundo grupo se materializan mediante formas morfológicamente complejas, donde, incluso, la marca del plural aparece duplicada. Hasta donde se nos alcanza, este tipo de variación en la expresión pronominal no ha sido analizada en detalle. El tipo de variación que más ha sido analizado en los estudios lingüísticos es el que deriva de la expresión o no de determinados rasgos morfosintácticos, tales como la distinción entre primera persona inclusiva y exclusiva -dependiendo de si el oyente está incluido en el conjunto referido por el pronombre- o a los distintos tipos de número (Corbett 2000, Wiese 2003). Me referiré a este segundo tipo de variación, ampliamente estudiado, como variación en accidentes morfológicos. Frente a esto, llamaré variación en forma morfológica a la ilustrada en (1), en la que los mismos rasgos reciben materializaciones morfológicas. Este trabajo trata de este segundo tipo de variación, que, según argumentaremos, está fundamentado sobre propiedades profundas, sintácticas y semánticas, de las lenguas naturales, lo cual nos permitirá dar cuenta de otros fenómenos aparentemente autónomos de las lenguas ilustradas en (1).

\section{TRES FENÓMENOS CORRELATIVOS}

En esta sección revisaremos tres fenómenos relacionados con los pronombres personales y observaremos que, en lenguas naturales sin 
relación tipológica entre sí, la presencia de uno implica la de los otros dos.

\subsection{Discordancias de persona}

El español, frente a otras lenguas, como el inglés, no admite discordancias de número entre el sujeto y el verbo principal (cf. 2) ${ }^{2}$.

(2) a. *El comité deciden prohibir las tasas.

b. Ing. The committee decide(s) to ban the taxes.

Sin embargo, las discordancias de persona no son imposibles en español, frente a otras lenguas (3).

(3) a. Los estudiantes queremos aprobar el examen.

b. Fr. *Les étudiants voulons passer l'examin.

Este fenómeno se restringe a los sujetos plurales y es, por tanto, agramatical en singular.

(4) *El estudiante quiero aprobar el examen.

Esta particularidad permite descartar un análisis que emplee la existencia de pronombres tácitos para explicar el contraste de (3). Se podría pensar, como se ha propuesto en la bibliografía del español, que en esta lengua la posición de sujeto estructural está siempre ocupada por un pronombre de este tipo y lo que parece ser el sujeto fonológicamente realizado es en realidad un tópico oracional. Dado que estos dos constituyentes serían independientes uno del otro, casos como los de (3) se explicarían porque los rasgos de persona del pronombre y los del tópico no son idénticos. El problema es que, incluso si resultara cierto que los sintagmas determinantes (SD) sujeto del español se encuentran en la posición de tópico ${ }^{3}$, este análisis no podría explicar por qué el fenómeno se restringe únicamente a los plurales ${ }^{4}$.

\footnotetext{
${ }^{2}$ Hay aparentes contraejemplos, como la oración El parlamento, cuando todos sus miembros se encontraban reunidos, decidieron prohibir las tasas. No obstante, este fenómeno está supeditado a la presencia de material fonológicamente realizado entre el sujeto y el verbo. La oración mejora cuanto mayor sea el material interpuesto entre ambos constituyentes, y empeora cuanto menor sea, lo cual sugiere que se trata de un problema de procesamiento y no propiamente de gramática.

${ }^{3}$ Motivos independientes suscitan dudas acerca de la propuesta de que estos SDs están en realidad en la posición de tópico. Aparte de que la estructura entonativa de los tópicos no es la de estas estructuras, fenómenos de elisión como el llamado Ascenso al nudo derecho indican que el verbo flexionado y el SD son un constituyente, lo cual sugiere que el SD debe estar en el mismo sintagma que el verbo: los estudiantes queremos, y los profesores intentáis, tener menos clases.

${ }^{4}$ Asimismo, no es tipológicamente cierto que las lenguas que parecen poseer pronombres tácitos admitan esta construcción. El italiano es una lengua pro-drop que, sin embargo, no tiene esta clase de discordancia, como prueba la agramaticalidad de gli studenti andiamo al cinema, vs. los estudiantes vamos al cine.
} 
Esta restricción sobre el número en las discordancias de persona es tan robusta que se extiende también a las formas de tratamiento. En ciertos dialectos meridionales, la forma de tratamiento usted, formalmente tercera persona aunque pragmáticamente se emplee para referirse al oyente, puede forzar una concordancia verbal en segunda persona. Dicha concordancia solo es posible en el plural ustedes, y nunca se ha documentado en el singular usted (4).

(4) a. Ustedes queréis aprobar el examen.

b. *Usted quieres aprobar el examen.

La discordancia también se documenta con ciertos pronombres en singular, pero, una vez más, son solamente aquellos pronombres que exigen una coda partitiva -que, por razones semánticas, ha de estar en plural- los únicos que admiten la discordancia.

(5) a. Cada uno (de los estudiantes) queremos aprobar.

b. Ninguno (de los estudiantes) queremos suspender.

Las mismas discordancias pueden producirse entre el clítico de objeto y un SD objeto directo o un sintagma preposicional (SP) objeto indirecto $^{5}$. Estas mismas discordancias se dan en catalán y en gallego (6).

(6) a. Cat. Ells estudiants hem pensat d' anar al cinema.

Los estudiantes hemos pensado ir al cine.

b. Gal. Os galegistas queremos un III estatuto de Galiza.

Los galleguistas queremos un III estatuto de Galicia.

Sin embargo, estos mismos casos son agramaticales no solo en inglés -donde la interpretación en la que la primera persona está incluida es imposible-y francés, sino también en italiano, portugués, coreano, árabe, egipcio y checo (7). Como se puede ver, no hay ninguna relación tipológica inmediata entre estas lenguas. Nótese, de hecho, que el fenómeno es rechazado por el portugués y aceptado por el gallego, pese a su indudable proximidad histórica, geográfica y tipológica, lo cual tambíen hace implausible un análisis mediante contacto de lenguas.

(7) a. It. *Gli studenti andiamo in cinema.

b. Port. *Os portugueses queremos un III estatuto.

c. Cor. *Ku enehakca-tul-un ene- uy phakoi- lul silehanta Def linguista. pl.TOP lenguaje-GEN destrucciónn-AC rechazar.

d. Ár. eg. *Al-misriyun naktubu l-kitab.

Def-egipcio.pl escribir.1pl. def-libro.

e. Che. *Studenti chceme udělat zkoušky.

Estudiante.pl. querer.1pl. aprobar examen.

\footnotetext{
${ }^{5}$ Una propiedad más de los sujetos plurales, que no trataremos en este trabajo, es la que recogen Bosque y Moreno 1984: solamente la forma plural permite que se interprete que el sujeto de la cláusula de infinitivo en un conjunto de personas entre las que se incluye el hablante en oraciones como no sabemos quiénes ir al cine-vs. * no sé quién(es) ir al cine-.
} 


\subsection{Modificación del pronombre mediante un sustantivo}

Lenguas como el inglés, el francés o el coreano admiten que un nombre modifique al pronombre personal, exclusivamente en las formas de primera y segunda persona del plural (8).

(8) a. Ing. We students.

b. Fr. Nous étudiants

c. Co. Wuli enehakca-tul-un

Nosotros estudiante.pl.TOP.

d. It. Noi studenti.

e. Che. My studenti.

f. Ár. eg. Nahnu- l- talibatun Nosotros- def- estudiante.pl

En cambio, el español, el catalán y el gallego no admiten esta misma modificación.

(9) a. Nosotros (*estudiantes)

b. Nosaltres (*estudiants)

c. Nosoutros (*estudiantes)

\subsection{Complejidad morfológica del pronombre}

Por último, hay una tercera propiedad que diferencia las lenguas del mundo, y que ya hemos mencionado: algunas lenguas materializan la primera y segunda persona del plural mediante una forma morfológicamente compleja (10).

(10) a. Esp. nos-otros

b. Cat. nos-altres

c. Gal. nos-outros

En otras lenguas del mundo, los mismos pronombres se realizan mediante formas morfológicas simples -ignorando provisionalmente la flexión de número-.

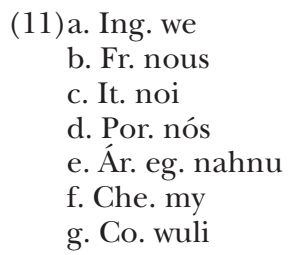

Obsérvese que ninguna de estas lenguas materializa ninguna diferencia adicional en el sistema personal, como el contraste entre primera persona inclusiva y exclusiva, bien documentado en las lenguas del mundo. Las formas morfológicamente complejas constan de un pronombre morfológicamente plural, muy próximo al clítico de objeto, y una forma 
del modificador otro, que comparte propiedades con los adjetivos y los determinantes (Eguren y Sánchez 2003), obligatoriamente en plural y, en algunos casos, flexionada también para género. Así, estos pronombres manifiestan doble marca de plural (12).

(12) nos - otr - $\quad$ o $\quad$ - $\quad$ o

1.pl.objeto modificador género plural

Hasta donde se me alcanza, ningún estudio ha tratado de explicar en un marco formal la doble marca de número de estos pronombres.

\subsection{Correlación entre las propiedades}

Las tres propiedades que hemos presentado se restringen a la primera y la segunda persona del plural, lo cual ya indica que debe existir alguna relación entre ellas. Además, como se puede ver en la tabla de (13), en las lenguas que estudiamos estas propiedades son correlativas. La presencia de pronombres morfológicamente complejos implica la ausencia de modificadores nominales y la posibilidad de tener discordancias de persona; la ausencia de pronombres morfológicamente complejos implica la ausencia de estas mismas discordancias y la posibilidad de tener modificadores nominales con los pronombres.

La correlación que vemos aquí, sistemática y biunívoca, hace deseable que una misma explicación pueda dar cuenta de las tres propiedades. En este artículo voy a proponer un análisis que dé cuenta de estos fenómenos de forma unificada.

\section{SUPOSICIONES TEÓRICAS}

En esta breve sección haremos explícitas las suposiciones acerca de ciertos aspectos teóricos sobre la relación entre la morfología y la sintaxis que configuran el marco de nuestro análisis.

\subsection{La relación entre el léxico y la sintaxis}

En los últimos años, distintas aproximaciones teóricas al léxico han propuesto que la relación entre la estructura sintáctica y la inserción de distintos elementos del léxico está mediatizada por reglas idiosincrásicas (Jackendoff 1990, Halle y Marantz 1993), que permiten dejar nudos sintácticos sin realización léxica o, incluso, insertar lexemas que no corresponden a ninguna posición sintáctica. En este trabajo, en cambio, nos ceñiremos al principio de que todo nudo sintáctico debe quedar 
legitimado por la inserción de un elemento del léxico. Enunciamos este principio, inspirado por Svenonius y Ramchand 2006, como el Principio de Exhaustividad Léxica (14).

(14) Principio de exhaustividad léxica:

Todos los rasgos presentes en la sintaxis deben ser lexicalizados.

Creemos que el principio de (14) es la hipótesis no marcada en la investigación de las relaciones entre el léxico y la sintaxis, ya que, en ausencia de contraejemplos claros, es más económica que una teoría que postule un nivel intermedio entre estos componentes.

\subsection{El principio del superconjunto y la inserción en nudos no terminales}

La siguiente pregunta es qué principio dicta cómo se produce la inserción de los elementos léxicos en la estructura sintáctica. Las aproximaciones que permiten el borrado de rasgos antes de la inserción léxica dictan que un elemento del léxico puede ser insertado en un nudo sintáctico si, y sólo si, el elemento del léxico contiene un subconjunto de los rasgos presentes en la sintaxis. Este principio suele ser conocido como el Principio del Subconjunto (Halle 1997). Por el contrario, en este trabajo vamos a seguir una propuesta alternativa de Starke -en trabajos no publicados-, desarrollada en detalle en Caha 2007, según la cual una pieza léxica puede ser insertada en un nudo siempre y cuando dicha pieza posea un superconjunto de los rasgos de ese nudo sintáctico. Este principio es conocido como el Principio del Superconjunto (cf. 15, adaptado de Caha 2007).

(15) Principio del superconjunto:

Una pieza léxica puede ser insertada en un nudo sintáctico si, y sólo si, posee un superconjunto de los rasgos presentes en dicho nudo. Cuando sea posible insertar varias piezas léxicas en el mismo nudo, tiene prioridad la que contenga menos rasgos no presentes en la sintaxis.

Es decir, no es posible dejar ningún rasgo presente en la sintaxis sin lexicalizar mediante inserción de alguna pieza de vocabulario, pero dichas piezas pueden contener rasgos que no estaban en la representación sintáctica y, por tanto, son redundantes. Caha 2007 demuestra que este principio permite predecir los fenómenos de sincretismo que se producen en distintas lenguas del mundo.

El Principio del Superconjunto tiene dos consecuencias que serán cruciales en este trabajo. La primera de ellas es que, al no permitir el borrado de rasgos sintácticos, no permite la inserción de una pieza léxica en un nudo sintáctico que contenga algún rasgo que no esté presente en la entrada de dicha pieza léxica. Es decir, si los rasgos de un nudo sintáctico son los de (16) y la lengua posee las piezas léxicas de (17), la inser- 
ción de (17b) no es posible, porque sus rasgos no son un superconjunto de los rasgos de la terminal sintáctica, pues hay un rasgo sintáctico, A, que quedaría sin identificar mediante esta inserción; sin embargo, la pieza de (17a) puede ser insertada en (16), pese a poseer un rasgo más que la representación sintáctica.

(16) Rasgos del nudo sintáctico: A, B, C, D, E

(17) Piezas léxicas.

$$
\begin{aligned}
& \text { a. I } \longleftrightarrow[\mathrm{A}, \mathrm{B}, \mathrm{C}, \mathrm{D}, \mathrm{E}, \mathrm{F}] \\
& \text { b. II } \longleftrightarrow[\mathrm{B}, \mathrm{C}, \mathrm{D}, \mathrm{E}]
\end{aligned}
$$

La segunda propiedad relevante del Principio del Superconjunto es que permite -aunque no exige- la inserción en cualquier nudo sintáctico, y no solamente en los nudos terminales. Es decir, existirían piezas léxicas que materializan fragmentos complejos de la representación sintáctica. Dado que las operaciones de ensamble sintáctico se pueden reducir a la teoría de conjuntos, cualquier nudo construido en el árbol representa un conjunto con más o menos miembros, y, por tanto, cualquier posición configuracional es igualmente legítima para permitir la inserción de una pieza léxica (cf. Neelemann y Széndroi 2006).

\subsection{Parsimonia de la proyección sintáctica}

Por último, en este trabajo seguiré un principio de parsimonia en la proyección sintáctica que dicta que solamente pueden proyectarse los nudos que posean rasgos. Este principio tiene consecuencias cruciales para el tratamiento de la proyección sintáctica del número en una lengua como el español, donde la única oposición de número es la que se produce entre el singular y el plural. En términos de rasgos, habría tres posibilidades para dar cuenta de esta situación: un rasgo equipolente (18a), dos rasgos independientes (18b) o un solo rasgo privativo (18c).

$$
\begin{aligned}
& \text { (18) a. +Plural, -Plural } \\
& \text { b. +Plural, +Singular } \\
& \text { c. +Plural }
\end{aligned}
$$

Para decidirnos por una de estas teorías, consideremos un sintagma nominal sujeto en un contexto genérico como el de (19). Como se puede ver, en este contexto el sustantivo aparece en singular, y, sin embargo, no hay ninguna presuposición acerca del número de individuos al que se refiera. La oración es verdadera en un universo en el que solo haya una ballena tanto como uno en el que haya más de una.

(19) La ballena se alimenta de pequeños animales.

La presencia del plural, en cambio, presupone la existencia de más de un individuo de la clase. La oración de (20) solo es verdadera en la 
medida en que se interprete aplicada a los sucesivos Papas que ha tenido la Iglesia a lo largo de su historia ${ }^{6}$.

(20) Los Papas son elegidos por el colegio cardenalicio.

Datos como los de (19) y (20) indican que lo que morfológicamente se manifiesta como singular no puede ser, literalmente, un rasgo semántico de singularidad ni un rasgo semántico de no pluralidad. La singularidad no presupone ni pluralidad ni ausencia de pluralidad, propiedad que queda de manifiesto en los contextos genéricos, mientras que la pluralidad presupone, justamente, pluralidad. Por tanto, concluimos que la singularidad morfológica es precisamente la ausencia de un rasgo de pluralidad y que la representación más acertada del plural es mediante un rasgo privativo. Si combinamos esta conclusión con el principio de parsimonia de la proyección sintáctica, la consecuencia es que los sustantivos singulares no se combinan con el sintagma número (21a); solamente los sustantivos plurales proyectan este núcleo (21b).
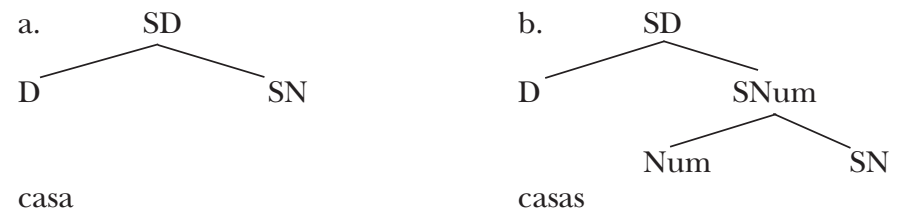

Esta asimetría en la representación tiene una consecuencia deseable, desde el punto de vista de la relación entre el léxico y la sintaxis, y es que en español el singular no está marcado por ningún morfema (22). Con la representación de (21a) no tendremos necesidad de hablar de morfemas cero, pues no habría ningún constituyente sintáctico con rasgos de número.

(22) casa, perro, cárcel, maná, pobre

\section{Modificación o Discordancia de PERSONA}

Tomemos el español como lengua representativa del grupo que permite discordancias de persona y el inglés como ejemplo del grupo que permite modificaciones. Los datos de (23) presentan de nuevo el contraste, que ocupará esta sección.

(23) a. Ing. The students want to go to the movies (\#El grupo de personas que

\footnotetext{
${ }^{6}$ Un aparente contraejemplo a esta generalización podría encontrarse en los objetos directos genéricos de oraciones como Juan vende pisos, que puede ser cierta tanto si Juan ha vendido un solo piso como si aún no ha vendido ninguno. Obsérvese, sin embargo, que en estos casos la presencia del plural es obligatoria en una clase semántica de sustantivos, los que denotan entidades contables, y en este contexto es crucial para permitir la lectura partitiva o genérica de dichos objetos. Por tanto, el plural tiene interpretación semántica en este contexto.
} 
quieren ir al cine incluye a los estudiantes, entre los que se encuentra el hablante o el oyente) / We students want to go to the movies.

b. Los estudiantes queremos ir al cine vs. *Nosotros estudiantes queremos ir al cine.

La interpretación de la oración gramatical de (23b) es precisamente la que se obtiene en la construcción inglesa con un modificador nominal del pronombre, esto es, que el grupo de estudiantes que quieren ir al cine incluye al hablante, del que se presupone que es, también, un estudiante. Esto indica que la interpretación semántica de las dos oraciones gramaticales en cada una de estas lenguas es la misma. Si admitimos la hipótesis del isomorfismo, esto es, que los aspectos estructurales del significado deben estar recogidos en la estructura configuracional de una frase, esto sugiere que el inglés y el español -y por ende, las lenguas de sus respectivos grupos- deben compartir una misma representación estructural.

Las oraciones gramaticales de (23) poseen dos predicaciones diferentes. La primera de ellas predica de un grupo determinado (we, los estudiantes) la propiedad de querer ir al cine. La segunda predicación, que es tácita en español, predica del hablante la propiedad de ser uno de los estudiantes. Centrémonos en esta segunda predicación. Esta predicación equivale a decir que la primera persona -junto con otros individuos- es un estudiante. Propongo representar esta estructura de predicación nominal mediante una cláusula mínima cuyo núcleo es el sintagma nominal y en cuyo especificador se proyecta el sujeto, la expresión referencial que incluye a la primera persona (we en inglés y rasgos de primera persona en español). En este diagrama no está representada la etiqueta categorial de la expresión referencial (cf. infra).

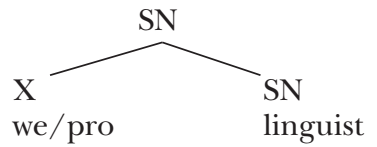

Nuestra representación de la predicación está en la línea de Stowell 1981 y se distancia tanto de Williams 1980, que propone una estructura plana para representar sintácticamente la predicación, como de Baker 2003, quien, siguiendo a Bowers 2000, propone que las categorías nominales no pueden ser predicados por sí mismos y necesitan combinarse con un núcleo funcional específico, el sintagma predicación, que las convierte en predicados e introduce en su especificador al sujeto de la predicación. Según creemos, parte del espíritu de la hipótesis de Stowell es la idea de que las etiquetas específicamente categoriales son irrelevantes a la hora de definir la configuración sintáctica y, por ello, todas ellas pueden actuar como predicados si se encuentran en la configuración adecuada. Esta idea es coherente con distintas propuestas recientes sobre la representación de las categorías gramaticales en la gramática (Marantz 1997, 2001). 
Esta estructura de cláusula mínima está dominada por las distintas proyecciones funcionales del SD. Solo emplearemos aquellas que se encuentran motivadas independientemente, con evidencia empírica interlingüística, en los estudios previos: el sintagma de número (SNum, cf. Ritter 1991) y al menos un sintagma determinante fuerte (sDF, cf. Zamparelli 2000), responsable de la lectura fuerte de los cuantificadores (Milsark 1974) y de la interpretación de ciertas expresiones definidas como constantes lógicas. Es posible que existan más proyecciones en el interior del SD, pero estas no son inmediatamente relevantes para nuestro análisis. La estrucura de un SD que incluya la cláusula mínima de (24) sería la de (25).

(25)

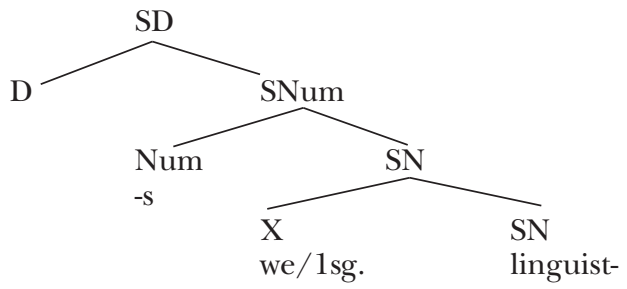

Es importante tener en cuenta que, siguiendo el principio de parsimonia de la proyección sintáctica, solamente se proyectará el SNum cuando éste contenga rasgos que proyectar. Es decir, si en una lengua con solo dos números, como el español, el singular es la ausencia de plural, en el singular no está presente el sintagma número.

\subsection{Justificación de la estructura predicativa}

Dechaine y Wiltschko 2002 proponen que la estructura de los modificadores nominales y los pronombres en estas lenguas es una configuración de núcleo-complemento. El nombre está introducido directamente en la posición de SN y el pronombre en la posición del determinante, como se observa en (26), donde sphi es una etiqueta que resume todas las posibles proyecciones funcionales que introducen los rasgos de género, número y persona en el SD.

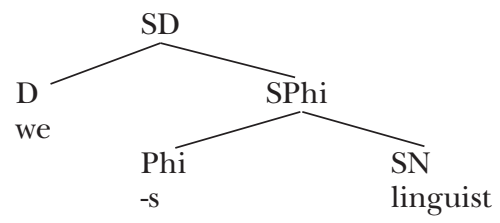

Es decir, para estas autoras, la relación que se establece entre el pronombre y el nombre es la misma que se establece entre el artículo defi- 
nido the y el nombre que introduce. Hay pruebas, no obstante, de que esto no es así.

Consideremos el caso del francés, que se comporta como el inglés en los fenómenos que estamos estudiando aquí. Como es sabido, el francés elide los segmentos / s / finales de palabra (27a). Esta regla fonológica no se aplica si la palabra va seguida por otra que comienza por vocal $(27 b)$, proceso de sandhi externo conocido como liaison.

(27) a. bonnes.

b. des bonne-[z] étudiants.

Pues bien: un sustantivo que comienza en vocal permite hacer la liaison de la -s final del artículo, como se ilustra en (28).

(28) le-s ([z]) étudiants.

Por el contrario, el mismo proceso no se aplica en las construcciones que nos ocupan en este caso.

(29) nou-s ([Ø]) étudiants.

Esto indica que la estructura que relaciona el pronombre con el sustantivo no puede ser la misma que relaciona el nombre con el artículo definido.

Este contraste puede tener una explicación en nuestra propuesta si la liaison no se aplica entre un núcleo y su especificador, sino solo entre núcleos y complementos. Esto equivale a proponer que los especificadores no forman un grupo fonológico con los núcleos de sus proyecciones, algo que puede estar independientemente motivado -cf., por ejemplo, la asimetría fonológica entre prefijos y sufijos (Fábregas 2004)-.

Una segunda prueba contra el análisis de Déchaine y Wiltschko se encuentra en construcciones inglesas como la de (30).

(30) we the people.

Déchaine y Wiltschko no predicen la existencia de estas estructuras, pero el análisis que he propuesto aquí permite generarlas. En este caso, el pronombre se encuentra en la posición de sujeto de una clásula mínima cuyo núcleo es el SD introducido por the $e^{7}$.

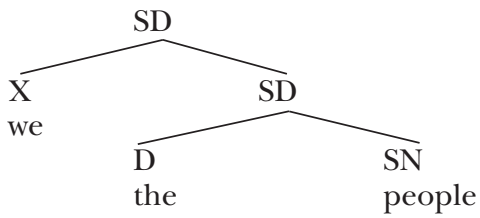

\footnotetext{
${ }^{7}$ Un análisis con SPred en la línea de Baker 2003 podría dar cuenta de estos fenómenos igualmente, ya que el sujeto estaría en la posición de especificador; sin embargo, el análisis queda descartado en la medida en que ningún morfema realizaría el núcleo de dicho SPred en español. Por tanto, nuestro análisis es más económico y permite una relación estricta entre léxico y sintaxis.
} 


\subsection{Diferencias entre las dos estructuras}

Nuestra propuesta es que las diferencias entre las dos estructuras no se deben a la configuración de sus elementos, que es idéntica en ambos casos, sino a la diferente estructura de rasgos que poseen los pronombres en cada grupo de lenguas. Concretamente, propongo que los pronombres we y you del inglés, y también en el resto de lenguas de su grupo, no poseen los rasgos de un determinante fuerte, sino de un cuantificador débil equivalente al español un en sus usos como variable lógica. En español y en las lenguas de su grupo, en cambio, el pronombre posee los rasgos de un determinante fuerte y su interpretación semántica es siempre la de una constante lógica, y, por ello, no es afectado por distintas clases de operador. Hay dos tipos de pruebas que permiten observar este contraste. La primera prueba es de carácter sintáctico y semántico. Pese a que Déchaine y Wiltschko 2002 proponen que los pronombres personales del inglés son constantes lógicas, Rullman 2004 observa que en inglés estos mismos pronombres personales tienen el comportamiento de variables lógicas en los casos relevantes. Considérese, por ejemplo, la correferencia parcial de las formas plurales we y you (32).

(32) Whenever I find a friend of mine, we go to the movies.

Hay dos interpretaciones posibles para esta oración en inglés. En una de ellas, we se comporta como una constante cuya referencia incluye a los mismos individuos en todas las situaciones. Por ejemplo, en el contexto en el que cada vez que el hablante se encuentra con un amigo, su hermano le propone ir al cine juntos -por ejemplo, porque quiere mantenerlo alejado de esos amigos-, el pronombre we es una constante lógica que se refiere siempre al hablante y a su hermano, sea quien sea el amigo que se encuentre. Sin embargo, también es posible una segunda lectura en la que el pronombre se comporta como una variable lógica, y es la interpretación más natural en que, cada vez que el hablante se encuentra con un amigo, le propone a éste ir juntos al cine. En este caso la referencia de we incluye al hablante y al amigo que se encuentre, sea quien sea, en cada caso ${ }^{8}$.

Lo interesante es que en español, catalán y gallego la misma oración, con pronombre expreso, admite solamente la lectura de constante lógica. (33) solo puede emplearse en la situación en que el hablante va con su hermano al cine cada vez que se encuentra con alguna de sus poco recomendables amistades.

(33) Cada vez que me encuentro con un amigo, nosotros vamos al cine.

Este es el comportamiento que se espera de un SD fuerte, mientras que en inglés el mismo pronombre exhibe las propiedades que esperamos de los cuantificadores débiles.

\footnotetext{
${ }^{8}$ La lectura de variable parcial puede estar bloqueada parcialmente por la existencia de pronombres tácitos en la lengua, interacción que no estudiaremos en este trabajo. Así, por ejemplo, en italiano la lectura de variable ligada con noi no resulta natural.
} 
Morfológicamente, también es posible encontrar pruebas de que los pronombres personales en las lenguas del grupo del inglés se comportan como cuantificadores débiles. Es bien sabido que el alemán estándar puede emplear dos tipos diferentes de flexión nominal, llamadas tradicionalmente fuerte y débil. Los determinantes emplean la declinación débil (34a), mientras que los indefinidos y los cuantificadores fuerzan el uso de la flexión fuerte (34b).

(34) a. Die schön-e Garten. Los hermosos jardines.

b. Zwei schön-en Garten. Dos hermosos jardines

Pues bien: en las estructuras en que un nombre modifica a un pronombre personal en alemán, la declinación fuerte es preferida a la débil (35).

(35) a. Wir Deutsch-en

b. ??Wir Deutsch-e

Nuevamente, en las lenguas del grupo del inglés, los pronombres personales se agrupan con los cuantificadores, no con los determinantes.

Siguiendo a Zamparelli 2000, la diferencia estructural entre los determinantes fuertes y los cuantificadores o determinantes débiles es que los segundos se sitúan estructuralmente en la posición en la que se gestiona la información cuantificacional del SD. El sintagma que contiene esta información en nuestro análisis es el sNum ${ }^{9}$. Es decir, en inglés y las lenguas de su grupo el pronombre personal debe desplazarse al snum cuando éste se encuentra presente. La forma de garantizar esta situación es proponer que el snum posee un rasgo de número no interpretable que le fuerza a concordar con Num y desplazarse a su especificador. En español y las lenguas de su grupo, en cambio, el pronombre no se desplaza a la misma posición y es, de hecho, una expresión referencial, por lo que proponemos que no posee este mismo rasgo. Los sustantivos, en cambio, poseen en ambos grupos de lenguas un rasgo no interpretable de número, pues tienen que concordar necesariamente con la información de número del sintagma completo. La comparación entre las dos lenguas se puede observar en (36).
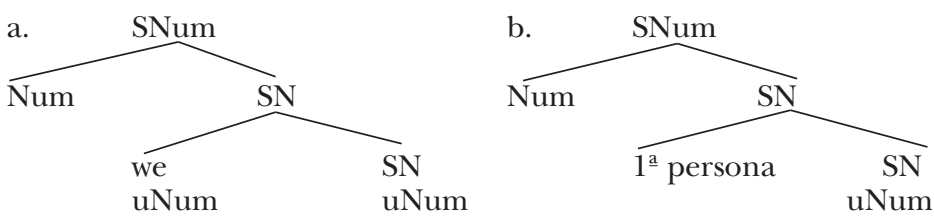

\footnotetext{
${ }^{9}$ Una consecuencia implícita de nuestro análisis es que lo que Zamparelli llama el Sintagma Determinante Débil es el mismo núcleo que Ritter 1991 o Borer 2004 llaman Sintagma de Número.
} 
El snum tiene la capacidad de cotejar el rasgo no interpretable de número de varios elementos, pues su rasgo de número es semánticamente interpretable y no queda inactivo tras un proceso de concordancia, pero, por hipótesis, solo puede atraer a un constituyente a su posición de especificador. Siguiendo la condición del eslabón mínimo (Chomsky 1995), si hay varios candidatos que pueden ser atraídos, solo el que se encuentre estructuralmente más alto se desplazará realmente al sintagma del elemento atractor. En términos jerárquicos, el elemento más alto es el pronombre, tanto en inglés como en español, pues solamente está dominado por un segmento de la categoría sN (Kayne 1994). Esto hace que de los dos posibles candidatos, en inglés sea el pronombre el que es atraído por sNum; el sustantivo coteja su rasgo de número in situ. Por el contrario, en español, el pronombre no puede ser atraído por el sNum, pues no existe ningún rasgo que ambos compartan, y, aunque sea el elemento más alto, no puede desplazarse al sNum. El único candidato que se puede desplazar es el sustantivo, que es el elemento atraído por el snum. Esto da lugar a las dos estructuras de (37).
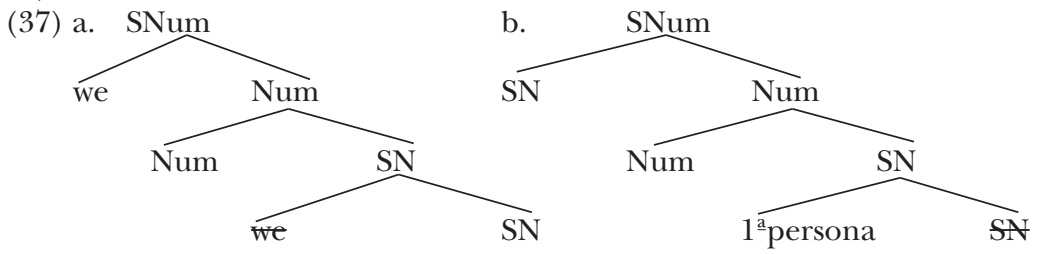

Nótese que esta configuración produce automáticamente en inglés la construcción del pronombre con un modificador, we linguists.

En cuanto al español, donde el pronombre tiene una interpretación necesariamente definida, se proyecta obligatoriamente un SD; en inglés, este segundo paso es irrelevante, y de hecho, es muy posible que a veces este sintagma se proyecte y a veces no, dependiendo de si la interpretación del pronombre es como constante o como variable.

Centrémonos, para terminar esta sección, en el caso del español. En español, como se sabe, los sustantivos pueden aparecer sin determinante de ningún tipo, por ejemplo en contextos predicativos (38a), pero los determinantes deben combinarse obligatoriamente con un sustantivo o alguna categoría asimilable al sustantivo (38b).

(38) a. Juana es médico.

b. *La es médico.

Esto sugiere que el determinante español tiene que cobinarse necesariamente con un nombre, lo cual se puede formalizar mediante un rasgo categorial no interpretable de sustantivo que le obliga a combinarse con un sustantivo para quedar formalmente legitimado. Cuando en español se proyecta el SD en una estructura como la de $(37 \mathrm{~b})$, el sustan- 
tivo coteja los rasgos con el sustantivo más próximo, que es lingüist-, con los rasgos de número correspondientes, presentes en el sNum (39).

(39)

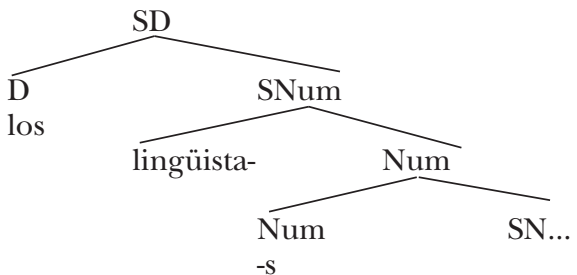

El pronombre de primera persona no llega a interactuar en ningún estadio de la derivación con el determinante, por lo que éste se materializa en la forma normal, los, pese a que todo el sintagma contiene un rasgo de primera persona gramatical que produce concordancia con el verbo. Esto da lugar, por fin, a las dos estructuras que queríamos generar, we linguists frente a los lingüistas queremos ir al cine.

\subsection{La obligatoriedad del plural y la lexicalización}

Esta estructura permite explicar por qué ambas construcciones son solo posibles en el plural una vez que nuestra propuesta se combina con el Principio del Superconjunto. Supongamos que piezas léxicas como lingüista en español y linguist en inglés son lexicalizaciones de un SN completo. Esta suposición no parece demasiado arriesgada, dado que estas palabras se materializan en español y en inglés precisamente en aquellos contextos en que tenemos pruebas independientes de la existencia de una estructura de SN. Por tanto, los rasgos que materializan estas piezas léxicas son los característicos de un SN (40).

(40) N, género.

La inserción del lexema se produce en el nudo SN más alto, que es el único que se puede definir como una categoría completa (Kayne 1994). Sin embargo, la estructura de cláusula mínima que combina el pronombre con este sustantivo hace que bajo el nudo SN existan otros rasgos que no son los que lexicalizan los temas nominales en estas lenguas. Específicamente, hay un rasgo de persona que no se encuentra en la entrada léxica del tema nominal; por ello, los rasgos de la pieza léxica no son un superconjunto del nudo sintáctico (41).

(41) Persona, N, género $<-* \rightarrow N$, género

Esto impide que se pueda producir la lexicalización de la estructura tal y como está, lo cual tiene consecuencias fatales. Es necesario, pues, que uno de los dos constituyentes de la cláusula mínima evacúe el nudo SN para que se pueda insertar alguna pieza léxica y la estructura quede legitimada. 
Esta es precisamente la función del sNum, la de proporcionar una posición de especificador que permita que los dos constituyentes de la cláusula mínima se separen. sNum atrae a uno de los dos constituyentes de la cláusula mínima, generando así una copia más alta, que, siguiendo las suposiciones básicas de la teoría de la realización fonológica de los constituyentes sintácticos, será la que se materialice.

En el caso del inglés, el pronombre es atraído al snum, el rasgo de persona se descarga mediante la inserción de we, su copia no se realiza, y en el nudo sN se puede insertar el tema nominal (42).

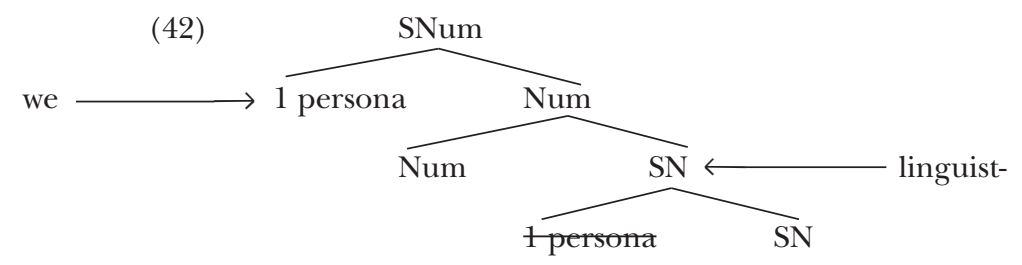

En el caso del español, es el sN el que es atraído al snum, donde, siendo la copia más alta, se lexicaliza mediante la inserción de lingüista-, y el pronombre personal queda in situ, donde es descargado mediante la inserción de un pronombre tácito (43).

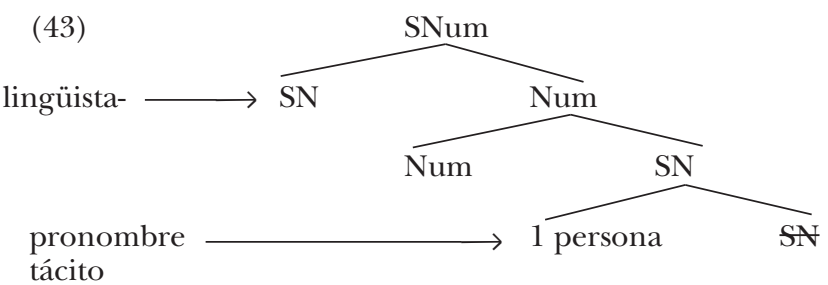

Lo que resulta indispensable para que la estructura sea gramatical es que uno de los dos constituyentes evacúe el sN que domina a la cláusula mínima. Es en este sentido en el que la presencia del sNum es crucial. En ausencia de rasgos de número, este sintagma no se proyecta, y, en consecuencia, no hay ningún nudo atractor que desplace ninguno de los dos constituyentes. De aquí se sigue, por un lado, la agramaticalidad de las modificaciones nominales de (44) en inglés y de las discordancias de (45) en español en singular.

(44) a. *I linguist

b. *You linguist

c. *He linguist

(45) a. *El estudiante quiero aprobar.

b. *El estudiante quieres aprobar.

La estructura que subyacería a estas construcciones sería la de (46), donde, como se ve, no hay posibilidad de lexicalizar el SN sin infringir el principio del superconjunto. 


\subsection{Contra un análisis en términos de la Restricción sobre los Pronombres Explícitos}

Una propuesta alternativa a la que estamos desarrollando en este artículo es que lo que bloquea la lectura de estos pronombres como variables es un efecto que tiene que ver con el diferente comportamiento de los pronombres explícitos y tácitos con respecto a la correferencialidad (en la línea de la Restricción sobre los Pronombres Explícitos de Moltalbetti 1984). Dado que las tres lenguas de las que hablamos aquí (esp., cat. gal.), además de contar con pronombres personales morfológicamente complejos, coinciden en ser lenguas de sujeto opcional, la contrastividad que presupone la presencia de una forma pronominal explícita bloquearía la lectura variable en oraciones como las estudiadas en 4.2. Si esto fuera así, no habría pruebas de que los pronombres personales del inglés sean cuantificadores, pues las diferencias se derivarían de la opcionalidad o no del sujeto.

Sin negar que la contrastividad del pronombre explícito puede afectar el fenómeno que estudiamos (recuérdese la nota 7 sobre el italiano), existen situaciones donde la contrastividad puede quedar neutralizada $y$, pese a todo, se observa que los pronombres del español rechazan una lectura variable que sí es posible en inglés. El primer caso relevante es el de (46).

(46) Siempre que me encuentro a un amigo, nosotros vamos al cine.

Supongamos un contexto discursivo donde se ha estado hablando previamente de las esposas de los amigos. Si la contrastividad del pronombre fuera el único problema para admitir la lectura del pronombre como una variable, (46) debería poder admitir una lectura en que cada vez que el hablante se encuentra con un amigo, termina yendo con la esposa de éste al cine. De hecho, esta lectura es perfectamente admisible en una oración como (47).

(47) Siempre que me encuentro a este amigo, nosotros vamos al cine.

En el contexto discursivo antes descrito, (47) admite la interpretación de que cada vez que el hablante se encuentra a Juan, termina en el cine con la esposa de éste. Queda de manifiesto, así, que la contrastividad que presupone la presencia explícita del pronombre personal no es incompatible con una lectura en la que nosotros se refiere al conjunto formado por el hablante y un referente que, sin estar presente en la oración, está discursivamente activado. El problema con la oración anterior, pues, es que la esposa es una variable cuya referencia cambia acorde con la referencia del amigo que, en cada caso, el hablante encuentra. La oración equivalente en inglés, (48), por el contrario, admite la lectura en que el pronombre subsume en su referencia la variable que se refiere al conjunto de las esposas de los amigos. 
(48) Whenever I find a friend, we go to the cinema.

Por tanto, incluso cuando la contrastividad del pronombre queda satisfecha mediante otros procedimientos, la lectura de variable es posible en inglés, pero no en español. Estos hechos quedan recogidos de forma directa si aceptamos que en inglés, pero no en español, los pronombres personales contienen una variable que hace posible la lectura observada anteriormente.

Otros casos apuntan en la misma dirección. Como se ha observado repetidamente, la oración de (49) es ambigua y admite una lectura de variable.

(49) In the exam, only I got a question that I could answer.

En una primera lectura, en la que el pronombre personal es una constante, del conjunto de preguntas que se hicieron en el examen, el hablante solo podía contestar una, que coincide con la que le hicieron a él. Es posible que las otras personas examinadas pudieran responder la pregunta que se les hizo a ellas. En la segunda lectura, el pronombre personal es una variable $\mathrm{x}$, y la oración quiere decir que el hablante fue la única x que tuvo la propiedad de ser capaz de responder la pregunta que se le hizo a x. En esta segunda lectura, ninguno de los otros examinados fue capaz de responder a la pregunta que se les hizo, y existe la posibilidad de que el hablante pudiera responder, adicionalmente, a las preguntas que se les hizo a los otros. Esta segunda lectura, como variable, es la que nos interesa en este momento. Confróntese esto con la oración de $(50)$.

(50) Solo yo recibí una llave que yo pudiera utilizar.

En esta oración, la segunda lectura, de variable, es imposible. El problema en este caso es que no está claro que la presencia del pronombre personal fuerce una lectura contrastiva, y esto es así debido a la forma verbal empleada. Determinadas formas del verbo español son homófonas en la tercera y primera personas, por lo que la oración de $(50)$, sin pronombre explícito, es ambigua en lo que se refiere a quién puede utilizar la llave: puede ser el hablante, que la recibe, o una tercera persona a la que va destinada dicha llave.

(51) Solo yo recibí una llave que pudiera utilizar.

La presencia del pronombre explícito, en este caso, debido a las particularidades morfológicas de la forma verbal, tiene una función desambiguadora y no meramente contrastiva. Pese a esto, la lectura de variable sigue siendo imposible, lo cual sugiere que los fenómenos a los que aludimos no pueden analizarse como un resultado independiente del parámetro del sujeto nulo.

En un sentido más teórico, la propia existencia de la restricción so- 
bre los pronombres explícitos de Montalbetti ha sido puesta en duda recientemente. Gürel 2003 muestra que en turco las posibilidades de correferencia del pronombre tácito y de la forma kendisi, ' $\{$ él / ella\} (mismo)' son iguales, de tal manera que ninguna de estos pronombres fuerza una lectura contrastiva. Por otro lado, los datos ofrecidos por Montalbetti no pueden ser tomados como una restricción absoluta a que toda variable lógica sea incapaz de funcionar como el antecedente de un pronombre explícito cuando el sujeto es opcional. Expresiones como cada estudiante o todo estudiante funcionan de forma natural en estos contextos, como prueba (52). Obsérvese, además, que la correferencialidad en la oración (53) mejora considerablemente cuando la oración principal aparece en subjuntivo o cuando se fuerza una lectura de foco de la oración subordinada.

(52) a. Cada estudiante está convencido de que él es el mejor alumno. b. Todo estudiante está seguro de que él ganará el premio.

(53) a. Nadie cree que él es tonto (sino que culpa a otro de sus errores).

b. Nadie cree que él sea tonto (sino que culpa a otro de sus errores).

\section{Cómo se obtiene nosotros}

En esta sección daremos cuenta de cómo la tercera pieza del rompecabezas, la presencia de pronombres personales morfológicamente complejos, se sigue de la estructura de rasgos presente en las lenguas de la clase del español.

Como se sabe, la interpretación semántica del número en la primera o segunda persona del plural no es la misma que se obtiene típicamente con un nombre común. El plural de (54) recibe una interpretación en la que hay un grupo de entidades $(G)$ con más de un miembro, todas ellas caracterizadas por poseer el mismo conjunto de propiedades, denotadas por el sustantivo flexionado.

(54) a. mesas

b. El plural denota a un conjunto $\mathrm{G}$ de más de un miembro tal que para todo objeto $\mathrm{x}$ que pertenece a $\mathrm{G}$ es cierto que [ mesa' $(\mathrm{x})$ ]

Es decir, para todo miembro del grupo G, debe ser cierto que de ese miembro se puede predicar que es una mesa. En cambio, la denotación de un plural como nosotros o we no es la misma. No es cierto que en el conjunto al que se refiere este pronombre todos los individuos tengan la propiedad de ser la primera persona, sino, más bien, que en dicho conjunto está incluido un individuo cuya propiedad es ser el emisor del enunciado. La interpretación en que el conjunto denota a más de una primera persona es, de hecho, semánticamente incoherente, ya que sabemos que los enunciados, en condiciones normales, tienen un solo emisor. 
Por tanto, las lenguas del mundo tienen que evitar que el pronombre con rasgos de primera persona, en el momento en que la estructura se interpreta semánticamente, haya establecido con el sNum una configuración tal que quede bajo el ámbito del operador de número plural. Es decir, la configuración que las lenguas del mundo evitan, porque forzaría, siguiendo el principio de isomorfismo entre forma y significado, la interpretación semánticamente incoherente, es la de (55), en que el elemento con rasgos de primera persona es el complemento del sNum.

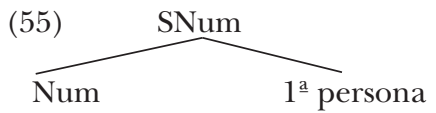

Las lenguas que pertenecen al grupo del inglés salvan esta configuración antes de la transferencia a la interfaz semántica, porque, como hemos visto, el constituyente con rasgos de primera persona posee, adicionalmente, un rasgo no interpretable de número que le permite escapar del ámbito del operador de pluralidad y, de hecho, lo coloca en una posición estructuralmente más alta.

(56)

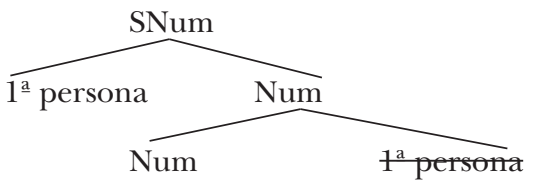

Las lenguas del grupo del español, en cambio, no tienen esta posibilidad, porque los rasgos de persona no se mueven de su posición de base. Sin embargo, existe una segunda opción para impedir que el SNum tome como complemento al pronombre de primera persona, y es que, en su lugar, este sintagma seleccione una categoría relacional que, a su vez, tome como uno de sus argumentos al pronombre de primera persona. Esta es la configuración que emplean las lenguas del grupo del español. En (57) se representa la configuración, en la que el núcleo relacional está representado como SCop.

(57)

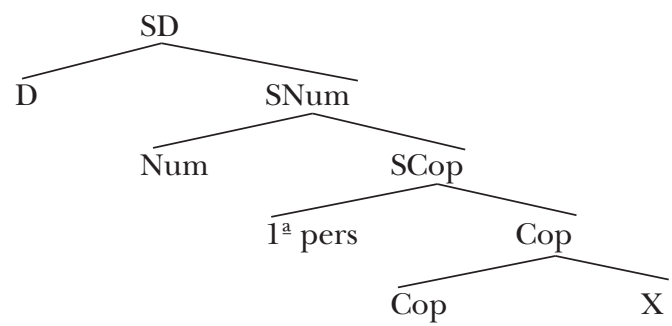

Proponemos que el elemento relacional que toma al pronombre de primera persona como su especificador es un sintagma copulativo (scop, Johannesen 1999), que selecciona como complemento a un constituyente cuyas propiedades pasamos a analizar a continuación. 
La interpretación de nosotros implica solamente que existe un grupo de al menos dos individuos en que uno de ellos es la primera persona, sin especificar las propiedades del otro miembro del grupo, que puede ser el oyente, alguien que no interviene en el discurso o ambos a la vez. La única condición que se impone a la interpretación de este segundo miembro del grupo es que sea una persona distinta de la primera persona. La imposibilidad de tener lecturas de variable parcial (cf. 32 y 33) indica que este segundo constituyente debe ser una constante lógica, es decir, referencial. Si tratamos de formalizar estas propiedades de $x$, requerimos que tenga un rasgo categorial de determinante, $\mathrm{D}$, que explique la referencialidad, y un rasgo semántico de constrastividad que explique que deba interpretarse siempre como una entidad diferente al hablante. Tanto el pronombre de primera persona como este D constrastivo carecen de un rasgo interpretable de pluralidad. Este rasgo se encuentra exclusivamente en el snum. Propongo que, en cambio, el determinante contrastivo tiene un rasgo de número no interpretable, debido al hecho de que el número de personas presentes en el grupo, junto al hablante, puede ser una o más de una. Por tanto, nuestra propuesta es que los rasgos de $\mathrm{x}$ son los que se enumeran en (58).

(58) D, constrastividad, uNum.

En cuanto a los rasgos del pronombre de primera persona del español, es necesario que contemplemos algunas de sus propiedades. En español, frente al inglés, el pronombre yo permite ser usado con el artículo, definido o indefinido, como un nombre común, sin forzar una lectura metalingüística (59a). En inglés, la única lectura posible de (59b) es aquella en que la forma I se refiere metalingüísticamente a una expresión utilizada en el discurso; esto no sucede en (59a).

(59) a. Tienes un yo hipertrofiado.

b. An $I$ is not a good word to start a report with.

Un yo no es una buena palabra para comenzar un informe.

Esta propiedad la comparten los pronombres personales del español con los nombres propios, expresiones que también permiten combinaciones con distintos determinante en contextos en que pierden su valor intrínsecamente referencial (un tal Carlos, los muchos Ramírez que viven en Madrid). Este fenómeno sugiere que en español los pronombres personales son, al igual que los nombres propios, sustantivos con capacidad referencial.

La segunda propiedad de los pronombres personales del español es que, frente a los demás sustantivos, no pueden tomar marcas de flexión de género o de número. Incluso en contextos donde la afijación con morfemas de plural está forzada por condiciones gramaticales independientes -como la necesidad de que los nombres contables sin determi- 
nante aparezcan en plural cuando son objetos directos-, el pronombre personal se resiste a admitir esta clase de morfemas (60).

(60) a. ??Los actores siempre tienen yos hipertrofiados.

Recordemos, por fin, que los determinantes del español deben combinarse obligatoriamente con un sustantivo para cotejar un rasgo categorial no interpretable, formalmente representado con la notación uN.

Siendo estos los rasgos de los constituyentes de la estructura de (48), veamos ahora cómo se genera la forma morfológicamente compleja nosotros. En el primer momento de la derivación, el núcleo Cop se proyecta y selecciona sus dos argumentos, el pronombre, de categoría N, y el elemento contrastivo, de categoría $\mathrm{D}^{10}$. En este punto, el sNum se proyecta y toma al SCop como complemento, estadio representado en (61).

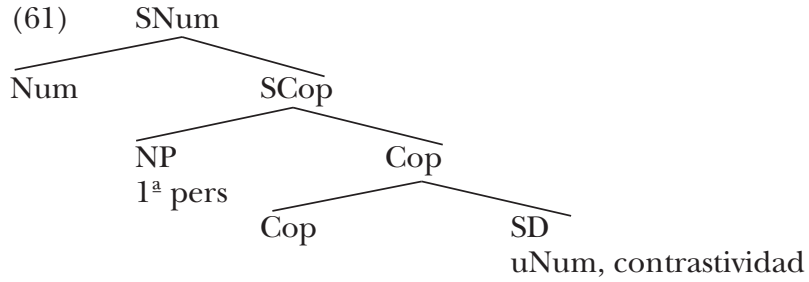

Una vez que se proyecta el sNum, $\mathrm{D}$, que tiene un rasgo no interpretable de número, es atraído por el sNum (62).

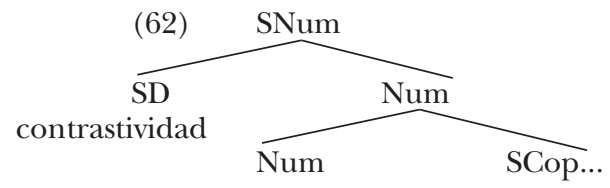

En este punto, el sintagma determinante (SD) se proyecta. Como hemos visto, los sintagmas determinantes del español tienen un rasgo no interpretable que les obliga a combinarse con un sustantivo; independientemente, sabemos que los determinantes concuerdan en número (y género) con las proyecciones que domina. Al proyectar el SD, obtenemos la configuración de (63).

\footnotetext{
${ }^{10}$ El SCop del interior del pronombre solo introduce dos constituyentes; esto contrasta con lo que sabemos del comportamiento sintáctico del SCop, que puede introducir un número ilimitado de constituyentes (Juan, María,[...] Pedro, Ana y Luisa). Nótese que la conjunción y debe aparecer obligatoriamente con un mínimo de dos constituyentes, por lo que parece ser un núcleo relacional que toma dos argumentos. El resto de constituyentes introducidos pueden ser especificadores múltiples atraídos por rasgos distintos a los que motivan la descarga argumental; es posible que, en caso de que estos rasgos se encuentren en Cop, no sea posible construir una palabra con la estructura y, en ese caso, la estructura pronominal se tendría que manifestar como un sintagma del tipo de yo, Juan [...] y otro.
} 
(63)

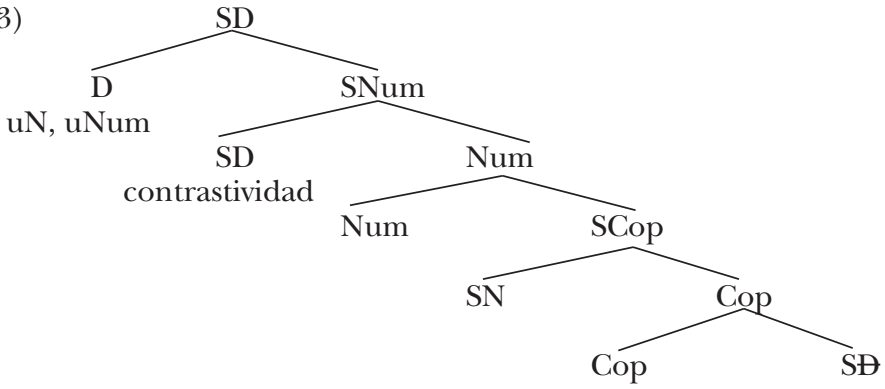

Los rasgos de número del determinante son cotejados con el sNum que éste selecciona; en cuanto al rasgo categorial no interpretable, como se puede comprobar en (63), el único elemento que puede cotejar ese rasgo es precisamente el pronombre personal, que es atraído por el SD a su especificador, lo cual da el resultado de (64).

(64)

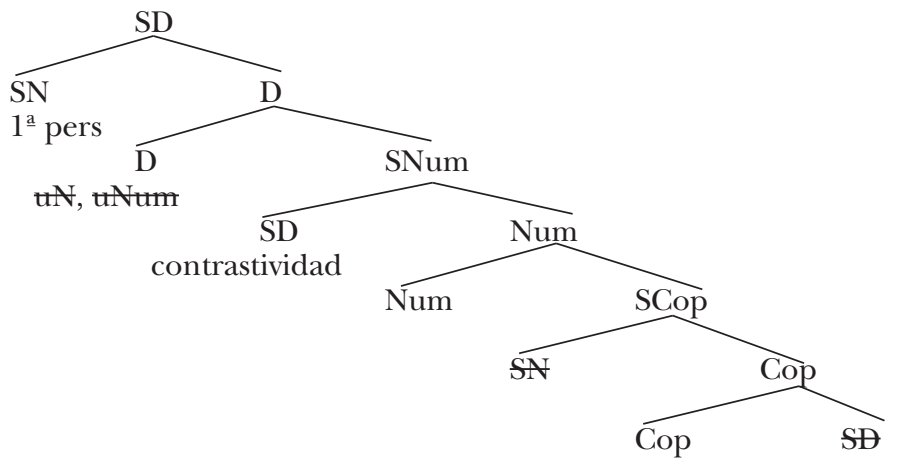

En este momento todos los rasgos no interpretables de la estructura han sido cotejados y es posible lexicalizar la estructura mediante la inserción de piezas léxicas particulares. Como han demostrado Eguren y Sánchez 2003, el elemento otro tiene propiedades de determinante (como la de legitimar sujetos preverbales) y está asociado nítidamente a un valor contrastivo. Por tanto, éste es el lexema que se inserta en el SD que se sitúa en el especificador de snum. En el núcleo Num se inserta el rasgo de número plural que denota la presencia de un grupo.

Por fin, el pronombre nos, que posee rasgos de primera persona y de pluralidad se inserta en el SD más alto, del que dependen los nudos que contienen rasgos de persona ( $\mathrm{SN}$ ) y rasgos de número plural (presentes en $\mathrm{D}$, obtenidos mediante concordancia con el sNum). El diagrama de (65) reproduce el proceso de lexicalización de la estructura; las flechas indican las posiciones en que cada lexema se inserta. 


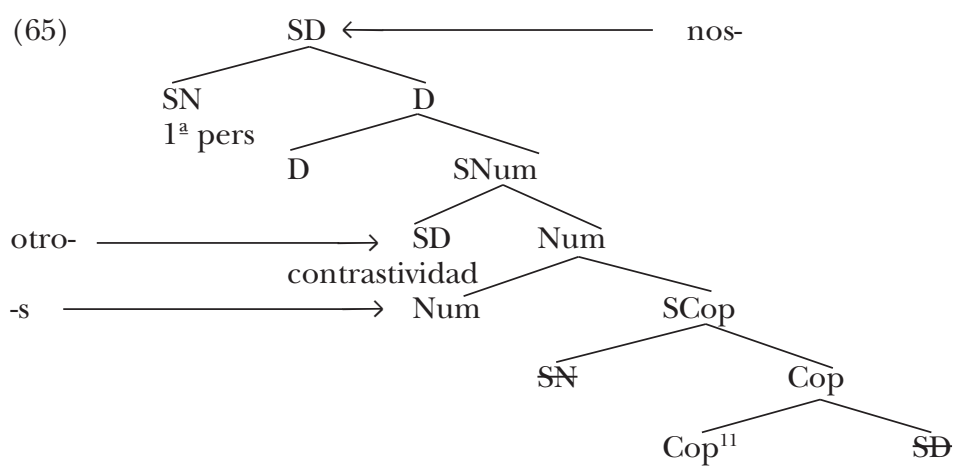

Es decir, el morfema nos no lexicaliza una forma de primera persona solamente, sino la unión de la forma de primera persona y un SD. Una prueba independiente de que nos es una variante del determinante con rasgos de primera persona se encuentra en ciertas variantes dialectales habladas en Canarias y en ciertas regiones de Sudamérica, en las que el pronombre de primera persona del plural es losotros (66).

(66) a. Oye, Venturilla, ¿losotros estamos caminando pa atrás o pa lante...? (Francisco Guerra, Los cuentos famosos de Pepe Moragas).

b. ¡Ajá, jodido! y ¿y quién sos vos? ¿Qué putás andás haciendo con losotros? (Víctor Cáceres, Humus).

En estos dialectos, la forma de primera persona no es atraída abiertamente al SD, de tal manera que la inserción de la forma nos quedaría bloqueada por la inserción de los.

\subsection{Predicciones de la teoría}

En esta sección revisaremos brevemente dos predicciones de nuestra propuesta. La primera de ellas tiene que ver con la segunda persona del plural. Pese a que no es concebible que un grupo de individuos sean, a la vez, emisores del mismo enunciado, sí se pueden concebir situaciones en las que un grupo de individuos sean, al mismo tiempo, receptores. Esto indica que es semánticamente posible manifestar la segunda persona del plural en un pronombre morfológicamente simple en el que falte, crucialmente, la segunda parte, introducida por -otros. Esta predicción queda confirmada por la existencia, en distintas variantes históricas o regionales del español, del pronombre vos, aunque pragmáticamente se emplee para referirse a un único receptor.

Si el problema de las formas morfológicamente simples de primera persona del plural es de naturaleza semántica, esperamos, asimismo,

\footnotetext{
${ }^{11}$ Una cuestión independiente es cómo se lexicalizan los núcleos coordinativos en el interior de las palabras. No tenemos una respuesta a esta pregunta, pero obsérvese que en compuestos con claro significado coordinativo, la lexicalización del núcleo parece, también, diferente a la normal (posiblemente cero): sadomasoquismo, hispano-alemán, etcétera.
} 
que, en aquellos casos en que los rasgos sean semánticamente no interpretables, el pronombre de primera persona del plural pueda ser morfológicamente simple. Esta segunda predicción también se cumple. Consideremos la oración de (67).

(67) Nos dijo a nosotros que saliéramos.

Si el clítico de objeto es una marca de concordancia verbal (Fernández Soriano 1989), entonces, al igual que cualquier otro constituyente concordado, no es interpretado en la semántica. Por esta razón, la forma del pronombre clítico puede ser morfológicamente simple, en contraste con el término de la preposición, que es el constituyente que motiva la concordancia, es semánticamente interpretable y, por ende, debe ser morfológicamente complejo.

\section{UNA NOTA HISTÓRICA SOBRE LA EVOLUCIÓN DE NOSOTROS Y VOSOTROS}

Creemos que los resultados de nuestro trabajo son compatibles con los estudios sobre la evolución histórica de los pronombres personales en español, al tiempo que pueden ayudar a entender algunos aspectos que, en nuestra opinión, no quedan del todo claros en los análisis existentes. Tomaremos como referencia el completo estudio de García y otros 1990, donde se estudia la evolución histórica de estas formas en gran detalle.

Una de las conclusiones fundamentales de estos autores es que la forma otros, que alternaba como complemento del pronombre con otras formas, como mismos y todos, aparece primero en la segunda persona, a la que añade un sentido claramente contrastivo que excluye a posibles terceras personas. A partir de ahí, la forma se extiende a la primera persona, y en este estadio el uso de la forma otros combinada con el pronombre permitía distinguir la primera persona inclusiva de la exclusiva mediante (cf. también Lenz 1925, pp. 228-229). En periodos más avanzados, la forma -otros se utiliza como una marca de énfasis que no implica necesariamente contrastividad.

El punto en el que encontramos problemas en el análisis de estos autores se refiere a la propuesta de que, después de esta fase, otros se encuentra desemantizado en el pronombre. La desemantización de -otros, según estos autores, culmina cuando dicho elemento se convierte en un exponente de pluralidad que, adicionalmente, aporta tonicidad al pronombre, de modo que las formas donde se combina el pronombre con otros contrastan con los clíticos nos y os.

Tratar la forma -otros como un exponente de pluralidad tiene, según nuestro criterio, algunos problemas. Dejando a un lado que -otros sería un afijo flexivo atípico, nótese que en el pronombre el plural ya está 
marcado en las formas nos y vos, por lo que no parece que exista la necesidad de buscar un segundo exponente. Por otro lado, surge la pregunta de por qué en ningún momento de la historia del español el hablante ha sentido la necesidad de reemplazar la forma -otros por otro constituyente que no invitara a confusión con el adjetivo determinativo otros. Como se puede observar, la forma -otros no está formalmente gramaticalizada en el sentido típico, pues no se encuentra reducida fonológicamente, ni ha sufrido cambios en su forma que sugieran que se ha producido un proceso de este tipo, al menos de la misma manera en que se ha producido en, por ejemplo, las formas del verbo haber convertidas en marcas de futuro. Resulta necesario, pues, dar alguna explicación sobre la preservación de -otros en estos pronombres.

En nuestro análisis, la forma -otros sigue teniendo valor contrastivo: introduce un referente que contrasta con la primera persona, lo cual produce la lectura de que nosotros se refiere a un conjunto compuesto por el hablante y al menos una persona que no es el hablante. En García y otros ob. cit., la contrastividad de otros no se produce internamente a la denotación del pronombre, sino que contrasta el conjunto de personas en el que se incluye el hablante o el oyente con otro conjunto de individuos.

Es decir: en los primeros estadios del uso de la forma compleja, -otros se comporta como esperamos de un modificador sintáctico típico, tomando la referencia del pronombre completo y estableciendo un contraste entre ésta y un conjunto externo a su denotación. El cambio diacrónico introduce la forma -otros en el interior de la palabra, en lo que podría ser una instancia de reanálisis; en este punto, el contraste se establece con los rasgos de primera o segunda persona. Desde esta perspectiva, -otros conserva su valor de contrastividad, pero, como sucede típicamente con las palabras, su valor semántico afecta a los constituyentes internos de esta unidad. En este sentido, el cambio histórico analiza un elemento sintácticamente independiente como parte de una palabra, lo cual es una evolución que ha sido observada repetidamente en el cambio diacrónico.

\section{CONCLUSIONES}

En este trabajo nos hemos aproximado a la variación morfológica desde una perspectiva que, según creemos, no es la habitual en los estudios tipológicos, pues nos hemos concentrado en la complejidad morfológica con que distintas lenguas expresan los mismos rasgos morfosintácticos.

Hemos mostrado cómo tres fenómenos en principio autónomos están conectados de forma profunda por los distintos rasgos sintácticos 
que poseen los pronombres en dos grupos de lenguas. Concretamente, hemos argumentado que en inglés y las lenguas que se comportan como este idioma en los fenómenos estudiados, los pronombres plurales son cuantificadores que deben entrar en concordancia con rasgos de número, cuando estos están presentes, mientras que en español y las lenguas de su grupo estos mismos elementos son determinantes fuertes que no entran directamente en concordancia con los rasgos de número. De esta situación se siguen consecuencias para la semántica, que fuerzan a las lenguas del grupo del español a introducir dichos pronombres en una estructura compleja.

En un nivel teórico, hemos argumentado a favor de una teoría de la morfología en la que el léxico refleja, de forma exhaustiva, los rasgos y configuraciones presentes en la sintaxis. Hemos empleado dos recursos técnicos cuya validez ha sido puesta a prueba en trabajos independientes, el Principio del Superconjunto (Caha 2007) y la lexicalización de segmentos completos de estructura (Neelemann y Széndroi 2006), y hemos demostrado cómo la aplicación de estos procedimientos puede dar resultados fructíferos en el estudio de la variación tipológica entre distintas lenguas o entre distintas variedades de la misma lengua.

\section{REFERENCIAS BIBLIOGRÁFICAS}

Abney, S. (1987): The English noun phrase in its sentential aspect, Tesis doctoral, Cambridge (Mass), MIT.

BAKer, M. (2003): Lexical categories. Nouns, verbs and adjectives, Cambridge, Cambridge University Press.

Bhat, D. N. S. (2004): Pronouns, Oxford, Oxford University Press.

Borer, H, (2004): Structuring sense, Vol. 1, In name only, Oxford, Oxford University Press.

Bosque, I. y Moreno, J. C. (1984): «A condition on quantifiers in LF», Linguistic Inquiry 15, 1, pp. 164-167.

Bowers, J. (2000): «Predication», en Baltin, M. y Collins, Ch. (eds.), The handbook of contemporary syntactic theory, Oxford, Blackwell, pp. 299-333.

CAHA, P. (2007): The shape of paradigms, Ms., CASTL, Universidad de Tromsoe.

CARdinaletti, A. (1994): «On the internal structure of pronominal DPs», The Linguistic Review 11, pp. 195-219.

- y STARKe, M. (1999): «The typology of structural deficiency: a case study of the three classes of pronouns», en Riemsdijk, Henk van (ed.), Clitics in the languages of Europe, Nueva York, Mouton de Gruyter, pp. 145-233.

Chomsky, N. (1995): The minimalist program, Cambridge (Mass.), мIт Press.

Corbett, G. (1991): Gender, Cambridge, Cambridge University Press.

- (2000): Number, Cambridge, Cambridge University Press.

Corver, N. y Delfitto, D (1999: "On the nature of pronoun movement», en Henk van Riemsdijk (ed.), Clitics in the languages of Europe, Berlín y Nueva York, Mouton de Gruyter, pp. 799-861. 
Déchaine, A.M. y Wiltschko, M. (2002): «Decomposing pronouns», Linguistic Inquiry 33, 3, pp. 409-442.

Eguren, L. y C. SÁnchez (2003: «La gramática de otro», Revista Española de Lingüistica, 33, 1, pp. 69-122.

Fábregas, A. (2004): "When prefixes escape», en Otoguro, R. y Galani, A. (eds.), York working papers in linguistics 2, pp. 1-22.

Fukui, N. (1987): Theory of projection in syntax, Stanford (CA), CSLI Publications.

García, E., de Jonge R., Nieunenhujjsen, D. y Lechner C. (1990): «(V)osotros: dos y el mismo cambio», NRFH 38, 1, pp. 63-133.

GÜREL, A. (2003): «Is the overt pronoun constraint universal? Evidence from L2 Turkish", en Liceras, J. M. y otros (eds.), Proceedings of the $6^{\text {th }}$ generative approaches to second language acquisition conference, Somerville (MA), Cascadilla Press, pp. 130-140.

Halle, M. (1997): «Distributed morphology: impoverishment and fission», en Bruening, B. y otros (eds.), PF: papers at the interface, Cambridge (Mass.), MIT Press, pp. 425-450.

- y Marantz, A. (1993): "Distributed morphology and the pieces of inflection», en Hale, K. y Keyser, S. J. (eds.), The view from building 20. Essays in honor of Sylvain Bromberger, Cambridge (Mass.), MIT Press, pp. 111-176.

Harbour, D. (2006): Morphosemantic number, Nueva York, Springer-Verlag.

Harley, H. y RitTer, E. (2002a): «Person and number in pronouns: a feature geometric analysis», Language 78, pp. 482-526.

- (2002b): «Structuring the bundle: a universal feature geometry», en Weise, H. y Simon, H. (eds.), Pronouns: grammar and representation, Amsterdam, John Benjamins, pp. 23-39.

Haspelmath, M. (1997): Indefinite pronouns, Oxford, Oxford University Press.

Jackendoff, R. (1990): Semantic structures, Cambridge (Mass.), mit Press.

Johannessen, J. B. (1998): Coordination, Oxford, Oxford University Press.

KAYne, R. (1994): The antisymmetry of syntax, Cambridge (Mass.), mit Press.

Koopman, H.( 2000): The syntax of specifiers and heads: collected essays of Hilda J. Koopman, Londres-Nueva York, Routledge.

Lenz, R. (1925): La oración y sus partes, Madrid, Centro de Estudios Históricos.

Marantz, A. (1997): «No escape from syntax: don't try morphological analysis in the privacy of your own lexicon», en Dimitridades, A., Siegel, L. y otros, University of Pensilvania working papers in linguistics, Vol. 4, 2, Proceedings of the 21 ${ }^{\text {st }}$ anual Penn linguistics colloquium, pp. 201-225.

- (2001): Words, Manuscrito, MIT.

Milsark, G. (1974): Existential sentences in english, Tesis doctoral, Cambridge (Mass.), MIT Press.

Montalbetti, M. M. (1984): After binding, Tesis doctoral, Cambridge (Mass.), MIT.

Neelemann, A. y Széndroi, K. (2007): "Radical pro-drop and the morphology of pronouns", Linguistic Inquiry, 38, 4, pp. 671-714.

Panagiotidis, P. (2002): Pronouns, clitics and empty nouns, Amsterdam, John Benjamins.

Postal, Paul M. (1969): «On the so-called pronouns in English», en Reibel, D. A. y Schane, S. A. (eds.), Modern studies in English, Nueva Jersey, PrenticeHall, pp. 201-224. 
RADFORD, A. (1993): «Head-hunting: on the trail of the nominal Janus», en Corbett, G. y otros (eds.), Heads in grammatical theory, Cambridge, Cambridge University Press. pp. 73-11.

RitTer, E. (1991): «Two functional categories in noun phrases: evidence from modern Hebrew», en Rothstein, S. (ed.), Syntax and semantics vol.25: perspectives on phrase structure: heads and licensing, San Diego, Academic Press, CA, pp. 37-62.

- (1995): «On the syntactic category of pronouns and agreement», Natural Language and Linguistic Theory 13, pp. 405-443

Rullman, H. (2004): «First and second person pronouns as bound variables», Linguistic Inquiry 35, 1, pp. 159-167.

STOWELl, T. (1981): Origins of phrase structure, Tesis doctoral, Cambridge (Mass.), MIT Press.

SvenONIUS, P. y RAmchand, G. (2006): Mapping a parochial lexicon into a universal semantics, Manuscrito, Universitetet i Tromso.

Williams, E. (1980): «Predication», Linguistic Inquiry 11, pp. 203-238.

ZAMPARELli, R. (2000): Layers in the determiner phrase, Nueva York, Garland. 